\title{
Dilated cardiomyopathy in dystrophic epidermolysis bullosa
}

\author{
R U Sidwell, R Yates, D Atherton
}

\begin{abstract}
Background-Dystrophic epidermolysis bullosa (DEB) is an uncommon genetic disorder of the skin and mucosae. In 1996, we reported the occurrence of lethal dilated cardiomyopathy (DCM) in two affected children.

Methods-In the past seven years we have routinely screened patients with severe DEB who have been under the care of this hospital by yearly clinical review, echocardiography, and quantification of plasma selenium and carnitine concentrations, as deficiency of these micronutrients is known to be associated with the development of DCM.

Results-Six of 61 children have developed DCM over the seven year period of this study, four of whom have not been previously reported, and three of whom have since died. We compared the concentrations of selenium and free and total carnitine in the children who developed DCM to concentrations in those with severe DEB who did not. The concentrations of free and total carnitine when first measured were significantly lower in the children with DCM, but the selenium concentrations were not.

Conclusions-We now believe that DCM is a not infrequent complication of severe recessive DEB, and may be related in part to carnitine concentrations, though the exact mechanism remains unclear. We therefore recommend that patients with this condition should undergo regular cardiac review including echocardiography. (Arch Dis Child 2000;83:59-63)
\end{abstract}

Keywords: dystrophic epidermolysis bullosa; dilated cardiomyopathy

Epidermolysis bullosa comprises a spectrum of genetic disorders in which adhesion of the skin and other epithelia to the underlying connective tissue is compromised. Recessive dystrophic epidermolysis bullosa (RDEB) is one of the most severe of these disorders, with blistering generally present from birth (fig 1). The adjective "dystrophic" refers to the characteristic atrophic scarring that follows healing of erosions in this disorder, which affects the squamous epithelia of the oropharynx, oesophagus, and anal canal, in addition to the skin.

The condition is caused by a defect in type VII collagen, which plays an important role in anchoring the epidermis to the basement membrane. ${ }^{1}$ Many different mutations have now been identified in the gene for type VII collagen (COL7A1), all resulting in dystrophic epidermolysis bullosa of varying degrees of severity. ${ }^{2}$
With good medical support, most children now survive into early adult life, when the combined effects of chronic malnutrition (due largely to dysphagia) and a greatly increased risk of squamous carcinoma result in premature death. Perhaps the greatest improvement in the care of these children has been the maintenance of nutrition, particularly through the use of gastrostomy feeding. ${ }^{3}$ Over the past few years, gastrostomies have been used at an increasingly early age and in a greater proportion of children. Supplements of selenium and carnitine are given if low serum concentrations are found. Monitoring of nutritional status is assisted by regular blood tests, and we aim to record a baseline set of results in all our patients.

Chronic anaemia is a feature of severe RDEB. This is mainly a result of iron deficiency, because of a combination of increased blood loss from the skin and gastrointestinal tract, and decreased iron intake in the diet. Therefore iron and folate supplements are given, but despite these, a proportion of patients will require blood transfusions.

Further complications for these children arise with the development of dilated cardiomyopathy (DCM). We previously reported the occurrence of DCM in two children with severe RDEB. ${ }^{4}$ There have been two other reported cases of DCM in dystrophic epidermolysis bullosa, one of unknown cause and the other possibly a result of iron overload in a 17 year old after multiple transfusions. ${ }^{56}$ For this reason, we have maintained a greater vigilance for this condition, which we have now identified in a further four patients.

\section{Patients and methods}

Of the children with dystrophic epidermolysis bullosa who attend this hospital, 61 have been diagnosed as having severe autosomal recessive disease on clinical and pathological grounds. These children undergo annual review, which, since 1992, has included detailed echocardiographic assessment to identify early features of cardiomyopathy.

The echocardiographic assessment includes a general evaluation of cardiac function on two dimensional imaging as well as $M$ mode measurements of left ventricular (LV) dimensions and function. Measurements are compared to normal values in children matched for body surface area. Identification of increasing LV dilatation or functional deterioration prompted increased vigilance with more frequent assessments of LV parameters. To date, at least one echocardiogram has been undertaken in 58 children.

We have monitored plasma selenium and carnitine concentrations in these children, because of the possible role of these micronutrients in the 


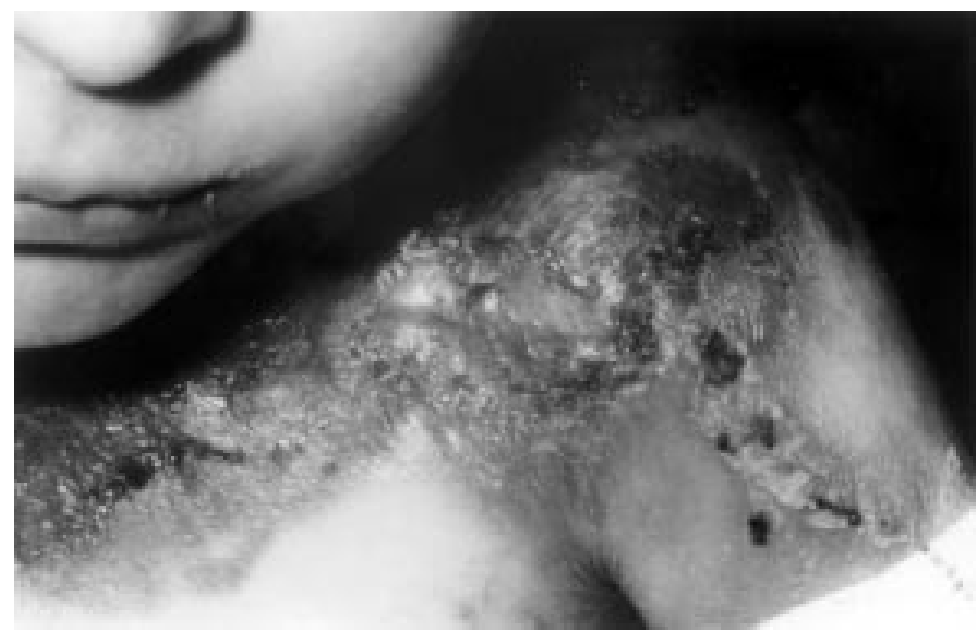

Figure 1 A child with recessive dystrophic epidermolysis bullosa. Note erosions and atrophic scarring of the skin. aetiology of dilated cardiomyopathy. Carnitine was measured using enzymatic assays which provide serum concentrations of total, free, and acyl carnitines. ${ }^{7}$ Selenium was measured using standard atomic absorption spectrometryhydride generation techniques. We have at least a baseline selenium, and total and free carnitine concentrations in 61 children.

\section{Results}

We have now observed the development of dilated cardiomyopathy in a total of six children with severe RDEB. Three of these have since died of their DCM; the other three remain alive (table 1 ).

All six patients were malnourished and had difficulty taking solids because of dysphagia. As a consequence, all had gastrostomies inserted (at varying ages), and supplements of vitamins, calories, protein, iron, zinc, selenium, and carnitine were given via the gastrostomy. There are no data on micronutrient status in patient 1 , but some data, though mostly postgastrostomy insertion, were obtained in the other patients. Plasma concentrations of selenium and carnitine were generally improved, often to within normal concentrations if previously low, after dietary supplementation via gastrostomy feeding (fig 2).

In patients 1,2 , and 3 there was rapid degeneration in cardiac function with death occurring from cardiac failure within months of diagnosis of a cardiomyopathy. The parents of these children did not consent to a full postmortem examination; however, those of patient $3 \mathrm{did}$ agree to a cardiac biopsy. This showed focal myocarditis with lymphocytic infiltration and interstitial oedema. There was no interstitial fibrosis and no myocyte hypertrophy. Stains for iron and amyloid were negative. The cardiac status of patients 4 and 5 has remained stable since the diagnosis of DCM. Patient 6 has shown a gradual decline in cardiac function (see table 1) since DCM was first noted, but has not yet required any cardiac therapy, and cardiac function continues to be monitored closely.

Comparison was made between the concentrations of total and free carnitine and selenium in the children with and those without a cardiomyopathy. The data were not skewed and therefore an unpaired $t$ test analysis was used. The concentrations of free and total carnitine, and selenium, in the initial blood samples taken (prior to any supplementation) in the children with DCM were compared to the initial blood samples of those who have not developed a DCM. Lower concentrations of free and total carnitine were found in the children who developed a DCM ( $p=0.006$; fig 3 ). The selenium concentrations were lower in the children with a DCM; however, this difference was not statistically significant.

A comparison was then made looking at all the blood concentrations of total and free carnitine and selenium obtained (these include both pre- and post-supplementation concentrations). The children with DCM were found to have lower mean concentrations of both free and total carnitine and selenium compared to the children who did not develop a DCM; however, this difference was not statistically significant. This analysis was repeated using age matched groups, which were considered to be more accurate. Again a similar difference was found between the mean concentrations of free and total carnitine and selenium in the two groups, though this was not statistically significant.

\section{Discussion}

Of the six children with severe RDEB and DCM described in this report, three deteriorated rapidly and died soon after the diagnosis was made. It is not clear whether the longer survival of the other three patients reflects better management of their nutrition, or perhaps a different aetiology of their DCM, or other factors.

Dilated cardiomyopathy has several causes, and its aetiology in these patients remains unclear. Possible causes include micronutrient deficiencies (in particular carnitine and selenium), infections, chronic anaemia, iron overload, and cardiomyopathy occurring as part of the disease process of severe RDEB itself.

Carnitine is a compound with an essential role in the transport of long chain fatty acids into the mitochondria where they then undergo fatty acid oxidation: a major source of energy for the heart.

Carnitine deficiency has been described in association with DCM resulting from both primary and secondary metabolic carnitine deficiency and in excessive loss. ${ }^{89}$ Reversibility of the cardiomyopathy with L-carnitine therapy has been shown, both in carnitine deficiency and in idiopathic DCM. ${ }^{10}$ Plasma carnitine status has been shown to correlate with prognosis in DCM, a lower acyl carnitine/free carnitine ratio having a more favourable outcome. ${ }^{11}$ Our results showed that the concentrations of free and total carnitine when first measured were significantly lower in the children with a DCM. These samples reflect amounts prior to dietary supplementation with carnitine and it may be that carnitine deficiency therefore contributed to the aetiology of DCM in these children. The analysis however was based on small numbers of patients and infrequent blood tests. Supplementation im- 
Table 1 Data on the children with RDEB who developed DCM (patients 1-6)

\begin{tabular}{|c|c|c|c|c|c|c|}
\hline Patient & 1 & 2 & 3 & 4 & 5 & 6 \\
\hline Parents & Unrelated Caucasian & $\begin{array}{l}\text { Consanginous } \\
\text { Pakistani }\end{array}$ & $\begin{array}{l}\text { Unrelated } \\
\text { Caucasian }\end{array}$ & $\begin{array}{l}\text { Unrelated } \\
\text { Caucasian }\end{array}$ & Unrelated Caucasian & $\begin{array}{l}\text { Unrelated } \\
\text { Caucasian }\end{array}$ \\
\hline Birth weight (kg) & $6 \mathrm{lb} 2 \mathrm{oz}$ & 2.95 & 2.4 & 3.4 & 3.35 & 4.1 \\
\hline $\begin{array}{l}\text { Skin biopsy confirmation of } \\
\text { DEB }\end{array}$ & No & Yes & Yes & Yes & Yes & Yes \\
\hline $\begin{array}{l}\text { Age at gastrostomy } \\
\text { insertion }(\mathrm{y})\end{array}$ & 10.5 & 4.6 & $\begin{array}{l}1.5 \text { (removed at } \\
1.7 \mathrm{y} ; \text { reinserted at } \\
3.5 \mathrm{y})\end{array}$ & 6 & 5.8 & 7.6 \\
\hline $\begin{array}{l}\text { Weight centile } \\
\text { pre-gastrostomy }\end{array}$ & $<3$ rd & $<3$ rd & $<3$ rd & $2 \mathrm{nd}$ & $<2$ nd & 9th \\
\hline $\begin{array}{l}\text { Weight centile } \\
\text { post-gastrostomy }\end{array}$ & $3 \mathrm{rd}$ & $<3$ rd & $<3$ rd & 25 th & $3 \mathrm{rd}$ & 25 th \\
\hline Haemoglobin $(\mathrm{g} / \mathrm{l})^{\star}$ & $88(60-100)$ & $100(60-116)$ & $67(50-82)$ & $89(51-134)$ & $94(54-118)$ & $98(86-111)$ \\
\hline Oral iron supplements & Yes & Yes & Yes & Yes & Yes & Yes \\
\hline Blood transfusion & 1 & 2 & 11 in total & 10 in total & 2 in total & None \\
\hline $\begin{array}{l}\text { Free carnitine }(\mu \mathrm{mol} / \mathrm{l}) \\
\quad(\text { normal range }=22-50)\end{array}$ & No levels & $20.9(6.7 \mathrm{y})$ & $\begin{array}{l}9(4.9 \mathrm{y}) \\
37(5.2 \mathrm{y})\end{array}$ & $\begin{array}{l}26(6.2 \mathrm{y}) \\
43(7.9 \mathrm{y}) \\
32(10.1 \mathrm{y})\end{array}$ & $\begin{array}{l}22(5.3 \mathrm{y}) \\
27(5.6 \mathrm{y}) \\
15(6.5 \mathrm{y}) \\
11(7.4 \mathrm{y}) \\
10(7.7 \mathrm{y}) \\
53(8 \mathrm{y}) \\
54(8.6 \mathrm{y})\end{array}$ & $\begin{array}{l}42(7.2 \mathrm{y}) \\
36(9.3 \mathrm{y})\end{array}$ \\
\hline $\begin{array}{l}\text { Total carnitine }(\mu \mathrm{mol} / \mathrm{l}) \\
\quad(\text { normal range }=26-62)\end{array}$ & No levels & No levels & $\begin{array}{l}12(4.9 \mathrm{y}) \\
38(5.2 \mathrm{y}) \\
27(5.4 \mathrm{y})\end{array}$ & $\begin{array}{l}32(6.2 \mathrm{y}) \\
51(7.9 \mathrm{y}) \\
37(10.1 \mathrm{y}) \\
37(10.5 \mathrm{y})\end{array}$ & $\begin{array}{l}29(5.3 \mathrm{y}) \\
37(5.8 \mathrm{y}) \\
19(6.5 \mathrm{y}) \\
31(7.4 \mathrm{y}) \\
15(7.7 \mathrm{y}) \\
56(8 \mathrm{y}) \\
70(8.6 \mathrm{y})\end{array}$ & $41(9.3 \mathrm{y})$ \\
\hline $\begin{array}{l}\text { Acyl carnitine }(\mu \mathrm{mol} / \mathrm{l}) \\
\quad(\text { normal range }=4-12)\end{array}$ & No levels & No levels & $\begin{array}{l}3(4.9 \mathrm{y}) \\
1(5.2 \mathrm{y})\end{array}$ & $5(10.1 \mathrm{y})$ & $\begin{array}{l}5(7.7 y) \\
3(8 y) \\
16(8.6 y)\end{array}$ & $5(9.3 \mathrm{y})$ \\
\hline $\begin{array}{l}\text { Selenium }(\mu \mathrm{mol} / 1) \text { (normal } \\
\quad \text { range }=0.7-1.7)\end{array}$ & No levels & $\begin{array}{l}0.53(6.3 \mathrm{y}) \\
0.7(6.7 \mathrm{y})\end{array}$ & $\begin{array}{l}0.61(3.5 \mathrm{y}) \\
0.8(4.6 \mathrm{y}) \\
0.71(4.9 \mathrm{y}) \\
0.6(5.2 \mathrm{y}) \\
0.77(5.4 \mathrm{y}) \\
0.47(5.7 \mathrm{y})\end{array}$ & $\begin{array}{l}0.5(6.2 \mathrm{y}) \\
1.04(7.2 \mathrm{y}) \\
1.02(7.9 \mathrm{y}) \\
1.1(8.8 \mathrm{y}) \\
0.82(10 \mathrm{y}) \\
0.93(10.5 \mathrm{y})\end{array}$ & $\begin{array}{l}0.42(5.3 \mathrm{y}) \\
0.72(5.6 \mathrm{y}) \\
0.72(5.8 \mathrm{y}) \\
0.81(7.4 \mathrm{y}) \\
0.82(7.7 \mathrm{y}) \\
0.95(8 \mathrm{y}) \\
1(8.3 \mathrm{y})\end{array}$ & $\begin{array}{l}1.08(6 \mathrm{y}) \\
1.21(7.2 \mathrm{y}) \\
1.03(8.3 \mathrm{y}) \\
0.98(9.3 \mathrm{y})\end{array}$ \\
\hline $\begin{array}{l}\text { Plasma albumin }(\mathrm{g} / \mathrm{l})^{\star} \\
\quad(\text { normal range }=35-55)\end{array}$ & $30(28-33)$ & $30(26-32)$ & $31.2(27-35)$ & $33.7(29-40)$ & $32.7(28-36)$ & $34(25-39)$ \\
\hline $\begin{array}{l}\text { Age at last normal } \\
\text { echocardiogram (y) }\end{array}$ & None performed & None performed & 4.5 & 9 & 8 & 6.9 \\
\hline \multirow[t]{2}{*}{$\begin{array}{l}\text { Abnormal echocardiogram } \\
\text { readings }\end{array}$} & $\begin{array}{l}12.5 \text { y: SF } 14 \% \text {; } \\
\text { dilated } \\
\text { cardiomyopathy }\end{array}$ & $6.7 \mathrm{y}: \mathrm{SF} 9 \%$ & 5.8 y: SF $16 \%$ & 9.9 y: SF $27 \%$ & 8.8 y: SF $27 \%$ & 8.3 y: SF $28 \%$ \\
\hline & & & 6.1 y: SF $20 \%$ & 10.5 y: SF $26 \%$ & $\begin{array}{l}\text { No change in repeat } \\
\text { echocardiograms }\end{array}$ & 9.3 y: SF $25 \%$ \\
\hline $\begin{array}{l}\text { Blood tests at time of } \\
\text { cardiomyopathy } \\
\text { diagnosis }\end{array}$ & $\begin{array}{l}\text { Coxsackie B, HHV } 6 \\
\text { (negative IgM); } \\
\text { autoantibody profile } \\
\text { (negative), creatinine } \\
\text { kinase (normal) }\end{array}$ & $\begin{array}{l}\text { Adenovirus, } \\
\text { Coxsackie B, } \\
\text { parvovirus, } \\
\text { influenza A and B, } \\
\text { Mycoplasma } \\
\text { (negative IgM); } \\
\text { autoantibody screen } \\
\text { (negative) }\end{array}$ & $\begin{array}{l}\text { Enteroviruses and } \\
\text { hepatitis B } \\
\text { (negative IgM) }\end{array}$ & $\begin{array}{l}\text { Enteroviruses } \\
\text { (negative IgM), } \\
\text { creatinine kinase } \\
\text { (normal) }\end{array}$ & & 9.8 y: SF $22 \%$ \\
\hline Clinical cardiac state & $\begin{array}{l}\text { Acute deterioration at } \\
12.5 \mathrm{y} ; \text { death at } 12.7 \mathrm{y}\end{array}$ & $\begin{array}{l}\text { Acute deterioration } \\
\text { at } 6.7 \mathrm{y} \text {; death at } \\
6.9 \mathrm{y}\end{array}$ & $\begin{array}{l}\text { Acute LVF at } 6.1 \mathrm{y} \\
\text { death at } 6.2 \mathrm{y}\end{array}$ & $\begin{array}{l}\text { Moderate } \\
\text { deterioration in } \\
\text { exercise tolerance; } \\
\text { remains alive }\end{array}$ & $\begin{array}{l}\text { No significant } \\
\text { cardiac symptoms; } \\
\text { remains alive }\end{array}$ & $\begin{array}{l}\text { No cardiac } \\
\text { therapy yet } \\
\text { required; remains } \\
\text { alive }\end{array}$ \\
\hline
\end{tabular}

Patients 1 and 2 previously reported in Melville et al. ${ }^{4}$

$\star$ Results expressed as mean (range).

proved these concentrations, reflected by the fact that no statistically significant difference was found when comparing all the concentrations of carnitine, both pre- and postsupplementation. It is important, in view of these findings, that adequate carnitine concentrations be maintained to protect against the development of DCM. We have not been able to show reversibility of the cardiomyopathy with carnitine treatment, but there has been little further progression in some of the patients once they were taking carnitine supplements.

Selenium deficiency is also associated with DCM. ${ }^{12}$ Selenium is a trace metal element and is a coenzyme for glutathione peroxidase, acting as an antioxidant. Dilated cardiomyopathy associated with low selenium was common in areas of China where there were low concentrations of selenium in the soil and was known as Keshan disease. ${ }^{13}$ This cardiomyopathy is also reversible with selenium therapy if commenced early in the disease process. Low concentrations of selenium were often found in our patients with severe RDEB. Lower concentrations of selenium were found in the children with DCM on analysis of the initial blood tests; however, this difference was not significant. The slightly reduced concentrations of this micronutrient in the children with DCM may merely reflect the fact that they were always among our most severely affected patients, with correspondingly poor general nutritional status.

Thiamine deficiency (vitamin $\mathrm{B}_{1}$ deficiency, beriberi) is another well documented cause of $\mathrm{DCM}^{14}$ and dramatic improvement is seen with supplementation. All our patients receive 

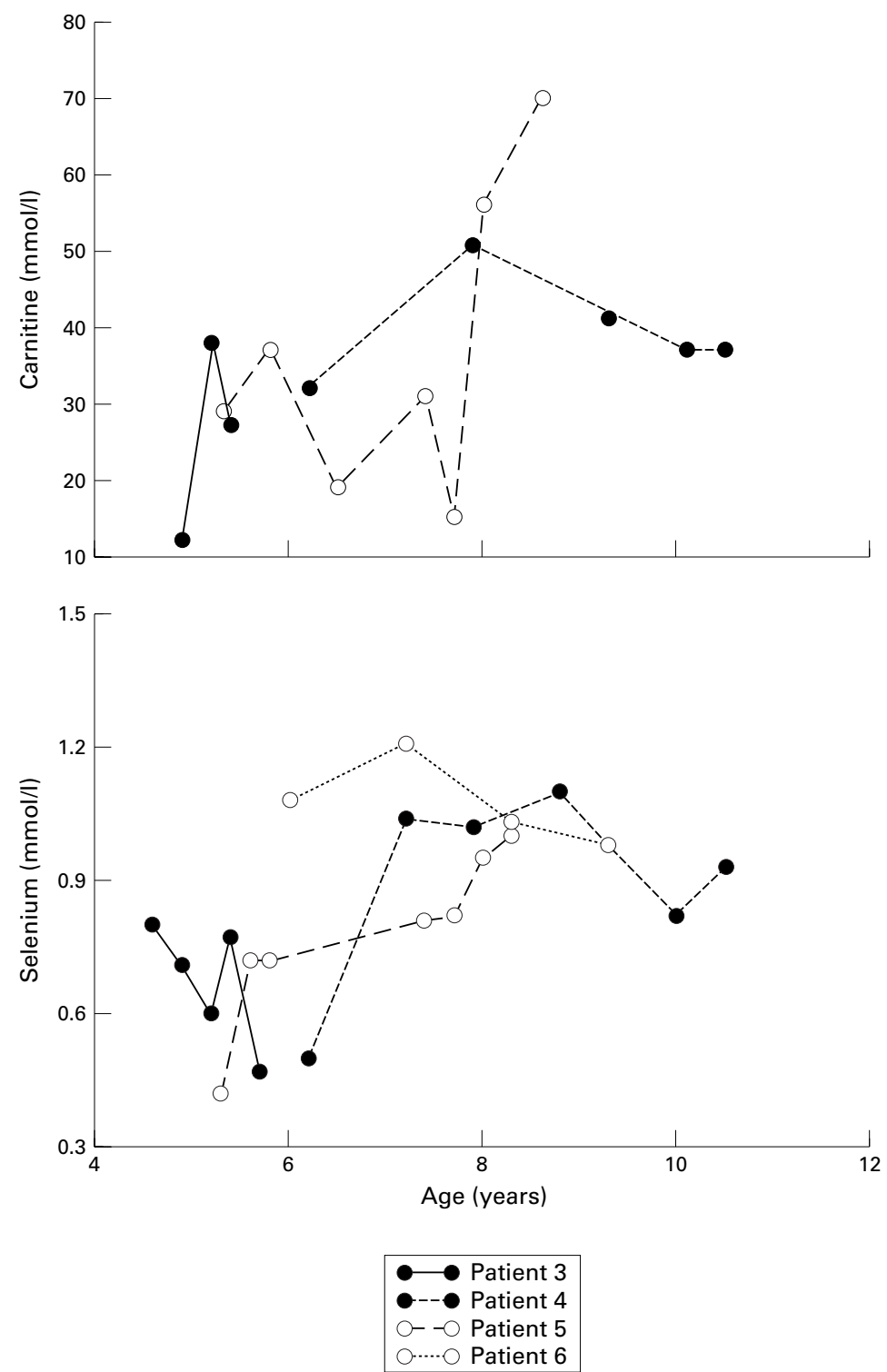

Figure 2 Selenium and carnitine status measured for patients 3, 4, 5, and 6.

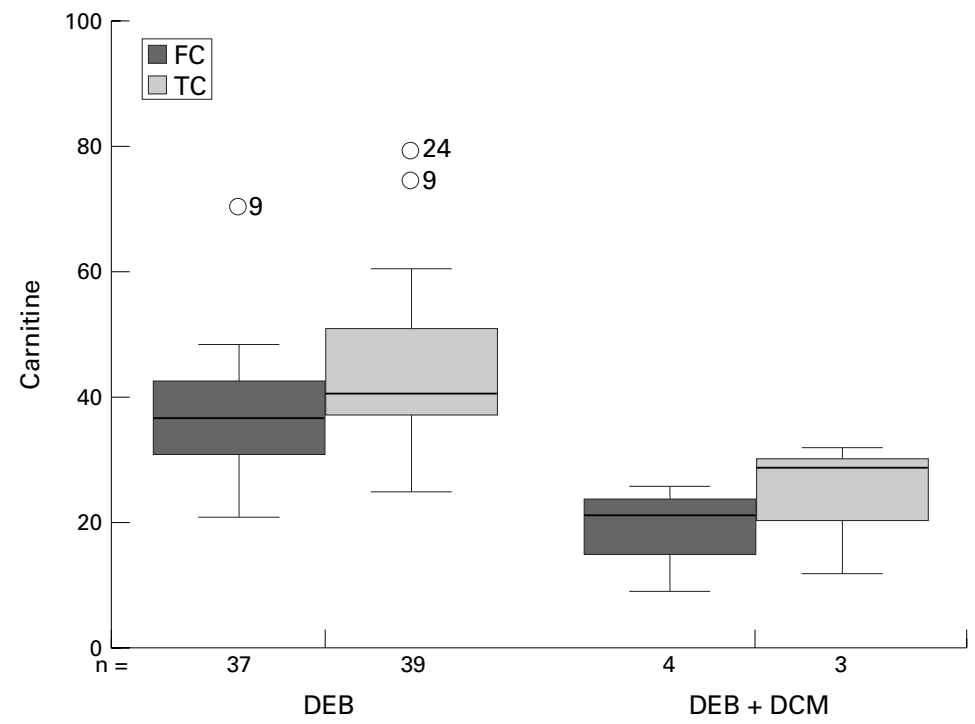

Figure 3 Box and whisker plots of free $(F C)$ and total carnitine (TC) concentrations in the children with RDEB only compared to those with RDEB and DCM. thiamine supplements, and we have always obtained normal concentrations when thiamine was measured (patients 3, 4, 5, and 6). Thiamine deficiency is therefore an unlikely aetiology in these patients.

There are many viral causes of DCM, including enteroviruses and hepatitis $\mathrm{C}$; in this situation the pathogenesis of the DCM is thought to be a post-infectious autoimmune process. ${ }^{15}{ }^{16}$ We found no evidence of viral infection in patients $1,2,3$, and 4 . Creatine kinase activity was also normal in patients 1 and 5, which argues against an inflammatory condition of the heart muscle. The single cardiac biopsy, however showed a picture of focal myocarditis with a lymphocytic infiltrate. The lack of fibrosis in the biopsy specimen suggested a short term condition, perhaps more consistent with a viral infection than a deficiency state. It is of course possible that this patient developed an acute myocarditis (viral or other aetiology) superimposed on a more insidious cardiac dysfunction of a different cause.

These children may be transfusion dependent and therefore iron overload needs to be considered as a cause of the cardiomyopathy. Our cases of DCM had a limited number of transfusions (mean 4.3, range 0-11). Iron overload is therefore unlikely, and this is supported by the negative iron stains on the cardiac biopsy specimen in patient 3, who had 11 transfusions.

Severe malnutrition can result in a dilated cardiomyopathy, and it may be impossible to implicate a single pathogenetic insult. The children more severely affected with RDEB have very poor nutrition, particularly prior to gastrostomy insertion and reflected by their low albumin concentrations. This may be an important factor in the development of DCM and emphasises the need for consideration of early gastrostomy insertion.

Finally, to look at the possibility that DCM is an inherent component of severe RDEB, we stained cardiac tissue from the hearts of six children unaffected by RDEB using the murine monoclonal antibody LH 7:2 (unpublished data). No expression of type VII collagen was found. This almost certainly excludes a direct effect of the mutation in COL7A1 on cardiac tissue.

In view of the substantial risk of dilated cardiomyopathy in severe RDEB this diagnosis should be considered in any patient with RDEB who develops cardiovascular symptoms. We now screen our patients routinely for evidence of dilated cardiomyopathy, but others may prefer not to do so in the absence of more effective therapy.

We would like to thank Professor Lake, consultant histopathologist; Richard Metcalf, biomedical scientist; Jacqueline Denyer, epidermolysis bullosa nurse specialist; Lesley Haynes, specialist dietitian in epidermolysis bullosa; Dr I Kovar, consultant dietitian in epidermolysis bullosa; Dr I Kovar, consultant paediatrician; David Smithson, Graphic Designer, Institute of Child Health, for their kind help with producing this paper. The statistical analysis was kindly performed by Sylvia Chalkley, Research Scientist, Niche Science and Technology Ltd and Academic Department of Child Health, ICMS, Chelsea and Westminster Hospital.

1 Uitto J, Pulkkinen L. Molecular complexity of the cutaneous basement membrane zone. Mol Biol Rep 1996;23:35-46. 
2 Jarvikallio A, Pulkkinen L, Uitto J. Molecular basis of dystrophic epidermolysis bullosa: mutations in the type VI

3 Haynes L, Atherton DJ, Ade-Ajayi N, Wheeler R, Kiely EM. Gastrostomy and growth in dystrophic epidermolysis bullosa. Br F Dermatol 1996;134:872-9.

4 Melville C, Atherton D, Burch M, Cohn A, Sullivan I. Fatal cardiomyopathy in dystrophic epidermolysis bullosa. $\mathrm{Br} F$ Dermatol 1996;135:603-6.

5 Brook MM, Weinhouse E, Jarenwattanon M, Nudel DB. Dilated cardiomyopathy complicating a case of epidermolysis bullosa dystrophica. Pediatr Dermatol 1989;6:21-3.

6 Sharratt GP, Lacson AG, Cornel G, Virmani S. Echocardiography of intracardiac filling defects in infants and children. Pediatr Cardiol 1986;7:189-94.

7 Roe DS, Terada N, Millington DS. Automated analysis for free and short chain acyl carnitine in plasma with a centrifugal analyser. American Association of Clinical Chemistry, 1992:2215-20.

8 Zales VR, Benson DW. Reversible cardiomyopathy due to carnitine deficiency from renal tubular wasting. Pediatr Cardiol 1995:16:76-8.

9 Squarcia U, Agnetti A, Caffarra A, Cavalli C, Marbini A. Dilated cardiomyopathy due to primary carnitine deficiency. Pediatr Med Chir 1986;8:157-61.
10 Kothari SS, Sharma M. L-carnitine in children with idiopathic dilated cardiomyopathy. Indian Heart $f$ 1998;61: $59-61$.

11 Marx M, Skyllouriotis M, Legenstein E, Proll E, Wimmer M. Plasma carnitine status: a prognostic factor in children with dilated cardiomyopathy. Amino Acids 1997:12:157-66.

$12 \mathrm{Li} \mathrm{Y,} \mathrm{Nan} \mathrm{BS.} \mathrm{Correlation} \mathrm{of} \mathrm{selenium,} \mathrm{glutathione}$ peroxidase activity and lipoperoxidation rates in dilated cardiomyopathy. Chin Med f 1989;102:670-1.

13 Li GS, Wang F, Kang D, Li C. Keshan disease: an endemic cardiomyopathy in China. Hum Pathol 1985;16:602-9.

14 Attas M, Hanley HG, Stultz D, Jones MR, McAllister RG. Fulminant beriberi heart disease with lactic acidosis: presentation of a case with evaluation of left ventricular function and review of pathophysiologic mechanisms. Circulation 1978;58:566-72.

15 Matsumori A. Molecular and immune mechanisms in the pathogenesis of cardiomyopathy - role of viruses, cytokines, and nitric oxide. Fpn Circ f 1997;61:275-91.

16 Muller S. Dilated cardiomyopathy-heart muscle disease of unknown origin or an autoimmune disease? New aspects of etiology, pathogenesis and clinical practice. Z Gesamte Inn Med 1989;44:469-76.

\section{TRANSATLANTIC TOPIC}

\section{ADHD: A new practice guideline from the American Academy of Pediatrics}

Attention deficit hyperactive disorder (ADHD) is the most common neurobehavioural disorder of childhood. However, the prevalence of ADHD and its diagnosis and treatment remain controversial. There are persistent concerns that ADHD is overdiagnosed, with the diagnosis reflecting poorly validated diagnostic criteria. In addition, parents, educators, and health care professionals are also concerned that psychoactive medications are being used to "calm" children inappropriately. The American Academy of Pediatrics recently released an important practice parameter (guideline) about the diagnosis and evaluation of children with ADHD. ${ }^{1}$ Much of the parameter was based on an enlightening and exhaustive review of the medical literature on $\mathrm{ADHD}$, which was performed by the McMaster group for the Agency for Healthcare Research and Quality (AHRQ, formerly the Agency for Healthcare Policy and Research). ${ }^{2} 3$

Highlights of the guideline include the observations that:

- The prevalence of ADHD in children from the US is between 7 and 10\% and is diagnosed more often in boys than girls

- Prevalence rates vary significantly depending on whether they reflect school samples $(6.9 \%)$ or community samples $(10.3 \%)$

- ADHD specific questionnaires, such as the Conners, are superior to non-specific questionnaires in differentiating children with ADHD from normal children

- Non-specific questionnaires (broad band scales) should not be used to diagnose children with ADHD

- In order to confirm the diagnosis, information is needed from various sources, usually from parents and the school

- Co-existing conditions are common (1/3 of children with ADHD) and include conduct disorder (26\%), depression (18\%), and oppositional defiant disorder $(35 \%)$; assessment for these conditions is recommended
- Other diagnostic tests, such as EEG, brain imaging, and thyroid hormone levels are not recommended.

For clinicians, certainly those in the United States, who evaluate, diagnose, and treat children with ADHD, the AAP's practice parameter is valuable. The American Academy of Child and Adolescent Psychiatry, American Academy of Family Physicians, Neurology Society, and Society for Pediatric Psychology have endorsed its recommendations. Other new literature that sheds light on this controversial topic includes the two reports from $\mathrm{AHRQ}^{2}{ }^{3}$ on diagnosis and treatment, and the results from a multicentre National Institutes of Health supported randomised controlled trial on treatment, which compared 14 months of medication management to intensive behavioural therapy. ${ }^{4}$ The results of this important study suggest that medication is superior to behavioural treatment and to routine community care for children with ADHD. Sadly, medication and behavioural therapy did not yield greater benefits than medication alone.

\section{H BAUCHNER MD} US Associate Editor

1 Committee on Quality Improvement, American Academy of Pediatrics. Clinical Practice Guideline: Diagnosis and evaluation of the child with attention-deficit/hyperactivity disorder. Pediatrics 2000;105:1158-70.

2 Agency for Health Care Policy and Research. Diagnosis of attention-deficit/ hyperactivity disorder. Rockville, MD: AHCPR, 1999: publication no.
99-0050.

3 Agency for Health Care Policy and Research. Treatment of attention-deficit/ hyperactivity disorder. Rockville, MD: AHCPR, 1999: publication no. 99-E018.

4 The MTA Cooperative Group. A 14-month randomized clinical trial of treatment strategies for attention-deficit/hyperactivity disorder. Arch Gen Psychiatry 1999;56:1073-86.

5 The MTA Cooperative Group. Moderators and mediators of treatment response for children with attention-deficit/hyperactivity disorder. Arch Gen Psychiatry 1999;56:1088-96. 